\title{
WHAT MOTIVATES REAL ESTATE INVESTORS
}

\author{
Isaura B Flores, University of North Texas at Dallas, Dallas, TX, U.S.A.
} Elizabeth Muniz, University of North Texas at Dallas, Dallas, TX, U.S.A.

dx.doi.org/10.18374/JIBE-20-1.6

\begin{abstract}
From the hierarchy of needs as identified by various scholars, housing is the second in hierarchy thus proving a cornerstone of human needs. Therefore, governments, both state and federal will be tasked to ensure housing policies are put in place to improve economic growth and development of its citizens. From this problem, there have been increased opportunities for private-public partnerships (PPPs) to reach out to the goal of provision of quality and affordable housing. This has led to boosting entrepreneurial culture in the real estate markets. The study seeks to give an insight into several factors concerning real estate entrepreneurial activities. The paper explains the motivations of entrepreneurial culture, objectives of the real estate investment, preference of real estate investments among entrepreneurs, the risk of real estate entrepreneurship and emerging trends in real estate investments.
\end{abstract}

Keywords: Real estate investor, motivation, real estate risk, capital restrictions, personal growth. 